\title{
Clinical study of the effect of refractive status on stereopsis in children with intermittent exotropia
}

\author{
Dong Han, Danni Jiang, Jiahuan Zhang, Tianxu Pei and Qi Zhao*
}

\begin{abstract}
Background: Many studies have shown that patients with intermittent exotropia have different degrees of damage to their stereopsis function. The purpose of this study is to explore the effect of different refractive status on stereopsis in children with intermittent exotropia(IXT).
\end{abstract}

Methods: We assessed 90 children of ages 4 16 years with intermittent exotropia at the Second Affiliated Hospital of Dalian Medical University during the years 2016-2017. According to their refractive status, the patients were divided into hyperopia group(spherical equivalent $>$ or $=-1.00$ diopters), myopia group(spherical equivalent $<$ or $=-1.00$ diopters), emmetropia group (spherical equivalent diopter: within $\pm 1.00 \mathrm{DS}$ ) and anisometropia group(binocular equivalent spherical difference $>$ or $=1.50$ diopter). The distant stereopsis of the patient was checked by the synoptophore, and the near stereopsis of the patients was checked by the Titmus stereogram. Then, we compared the difference between distant stereopsis and near stereopsis in the four groups.

Results: (1)The retention rates of distant stereopsis in the hyperopia group, emmetropia group, myopia group and anisometropia group were 33.3, 45.2, 34.6, and 33.3\%, respectively. There was no significant difference between the groups with different refractive status. (2)The retention rates of near stereopsis in the hyperopia group, emmetropia group, myopia group and anisometropia group were $66.7,83.9,80.8$, and $55.6 \%$, respectively. There were statistically significant differences between the emmetropia group and the anisometropia group $(P=0.030)$. (3)The retention rate of distant stereopsis in children with intermittent exotropia was 37.8\%, and the retention rate of near stereopsis was 74 . $4 \%$. The difference between the two groups was statistically significant $(P=0.019)$.

Conclusions: The damage to distant stereopsis in children with intermittent exotropia is more serious than that to near stereopsis. The damage to near stereopsis in children with intermittent exotropia and anisometropiais more serious.

Keywords: Intermittent exotropia, Stereopsis, Refractive status

\section{Background}

Intermittent exotropia (IXT) is a transitional strabismus between exophorias and constant exotropia, accounting for $50 \% \sim 90 \%$ of exotropia [1]. It usually occurs before the age of 5 . Women are more commonly affected than men, and Asians have a high incidence [2, 3]. Especially in China, the prevalence rate is estimated to be 3.9\% [4]. Many studies have shown that patients with intermittent exotropia have different degrees of damage to their stereopsis function and that intermittent exotropia is more common with refractive error $[5,6]$. Studies have shown that patients with

\footnotetext{
* Correspondence: zhaoqi6xia@163.com

The Second Affiliated Hospital of Dalian Medical University, Dalian, China
}

intermittent exotropia usually have binocular foveal gaze and normal near stereopsis, [7] while other studies suggest that some patients with intermittent exotropia exhibit near stereopsis decline [8]. To investigate the effect of refractive error on the stereopsis in patients with intermittent exotropia, we summarized the clinical data of 90 patients with intermittent exotropia.

\footnotetext{
Methods

Subjects investigated

We assessed 90 children with intermittent exotropia in the pediatric ophthalmology clinic of the Second Affiliated Hospital of Dalian Medical University during the
} 
years 2016-2017. The study was approved by the Ethics Committee of the Second Affiliated Hospital of Dalian Medical University and it was performed in accordance with the tenets of the Declaration of Helsinki. A verbal consent was obtained from the parents of patients, and the oral consent has been approved by the Ethics Committee of the Second Affiliated Hospital of Dalian Medical University. Their mean age was $(7.73+2.83)$ years, and they included 48 males and 42 females. Inclusion criteria were as follows: (1)the diagnosis of intermittent exotropia is clear. (2) Strabismus degree $>$ or $=15$. (3) Age of $4 \sim 16$ years. (4) Ability to cooperate with astereopsis examination. (5) No monocular or binocular amblyopia and other ocular or systemic diseases.

\section{Division into groups}

According to the refractive status, the subjects were divided into 4 groups: (1) the hyperopia group(spherical equivalent $>$ or $=-1.00$ diopters), (2) the myopia group(spherical equivalent $<$ or $=-1.00$ diopters), (3) the emmetropia group (spherical equivalent diopter: within \pm 1 .00DS) and (4) the anisometropia group (binocular equivalent spherical difference $>$ or $=1.50$ diopter).

\section{Test methods}

The clinical examination included the eye position, eye movement, visual acuity, prism cover test, cycloplegia, stereopsis examination, slit lamp examination, and fundus examination-all of which were analyzed by experienced ophthalmologists and optometrists.

(1) The refractive status was examined by experienced optometrists after cycloplegia, with $1 \%$ atropine sulfate eye gel for subjects younger than 12 years and with compound tropicamide mydriatic eye drops for subjects older than 12 years.

(2) We applied a synoptophore to examine for distant stereopsis. Binocular simultaneous vision was checked using printed pictures, one of a car and the other of a door; in this way, we could identify whether there was a coincident point. Then, we checked the fusion function using printed pictures with a butterfly and a cat, and we could determine whether there was a fusion function. We examined distant stereopsis using qualitative and quantitative analysis of stereoscopic pictures. The results were divided into existent distant stereopsis and nonexistent distant stereopsis. After that, we used a Titmus stereogram to examine near stereopsis, and the patients could identify the contents of the maximal arcsec picture recorded as existent near stereopsis, otherwise, the record was without near stereopsis.
(3) We used the corneal reflection method and prism neutralization method to determine the nature of the strabismus and strabismus degree.

\section{Statistical method}

We applied SPSS 20.0 statistical analysis software for the data analysis. The variance analysis was used to measure the age, strabismus degree and other measurement data among the four groups. Enumeration data of the number of patients with or without stereopsis was performed using the chi square test, and the independent sample t-test was used to measure the measurement data between the two groups. $(P<0.05$ was considered statistically significant.)

\section{Results}

There were 90 patients with intermittent exotropia, and their mean age was $7.73+2.83$ years. The average near strabismus degree was $(36.89 \pm 8.06)$, and the average distant strabismus degree was $(35.83 \pm 13.62)$. The retention rate of distant stereopsis in the emmetropia group was $45.2 \%$, while that of the children with refractive error was 33.9\%; however, there was no significant difference between the two groups $(P=0.295)$. The retention rate of near stereopsis in the emmetropia group was $83.8 \%$, while that of the children with refractive error was $69.5 \%$; however, there was no significant difference between the two groups $(P=0.137)$. The mean age, deflection of eye position and average spherical equivalent of the intermittent exotropia patients with different refractive statuses are listed in Table 1.

As shown in Table 2, The retention rates of distant stereopsis in children with intermittent exotropia was 37.8\%, and the retention rate of near stereopsis was $74.4 \%$. The difference between the two groups was statistically significant $(P=0.019)$. The retention rates of distant stereopsis in the hyperopia group, emmetropia group, myopia group and anisometropia group were $33.3,45.2,34.6$, and $33.3 \%$, respectively. The results revealed that the emmetropic group's distant stereopsis retention rate was higher than that of the other three groups, but there was no significant difference among groups $(P=0.775)$. There was no significant difference between the groups with different refractive statuses. The retention rates of near stereopsis in the hyperopia group, emmetropia group, myopia group and anisometropia group were $66.7,83.9,80.8$, and $55.6 \%$, respectively. The retention rates of near stereopsis in the emmetropia group and myopia group were higher than those in the hyperopia group and anisometropia group. There was no significant difference between the anisometropia group and the myopia group $(P=0.071)$. but The difference between the anisometropia group and the emmetropia group was statistically significant $(P=0.030)$. 
Table 1 General conditions in patients with intermittent exotropia

\begin{tabular}{lllllll}
\hline $\begin{array}{l}\text { Refractive } \\
\text { status }\end{array}$ & Number & Age(years) & $\begin{array}{l}\text { Right spherical } \\
\text { equivalent(D) }\end{array}$ & $\begin{array}{l}\text { Left spherical } \\
\text { equivalent(D) }\end{array}$ & $\begin{array}{l}\text { Near strabismus } \\
\text { degree }\end{array}$ & $\begin{array}{l}\text { Distant strabismus } \\
\text { degree }\end{array}$ \\
\hline Hyperopia & 15 & $6.06 \pm 1.53$ & $2.45 \pm 0.93$ & $2.60 \pm 0.98$ & $37.33 \pm 5.94$ & $38.33 \pm 6.45$ \\
Emmetropia & 31 & $7.14 \pm 2.98$ & $0.01 \pm 0.52$ & $-0.02 \pm 0.60$ & $35.00 \pm 6.32$ & $35.97 \pm 6.11$ \\
Myopia & 26 & $8.63 \pm 2.48$ & $-2.19 \pm 1.19$ & $-2.24 \pm 1.22$ & $35.96 \pm 8.13$ & $30.77 \pm 21.71$ \\
Anisometropia & 18 & $8.84 \pm 3.11$ & $-1.82 \pm 1.77$ & $-2.38 \pm 2.17$ & $41.11 \pm 10.79$ & $40.83 \pm 10.33$ \\
F & & 4.454 & 64.315 & 58.938 & 2.461 & 2.269 \\
P & & 0.006 & 0.000 & 0.000 & 0.068 & 0.086 \\
Total & 90 & & & & & \\
\hline
\end{tabular}

\section{Discussion}

Intermittent exotropia is the most common type of exotropia in the clinic. Among children with strabismus, the proportion with IXT has been reported to vary greatly by country, from $17 \%$ in the United States to $66 \%$ in Singapore, [9] and it accounts for approximately $25 \%$ of strabismus in children in the Western world [10, 11] and $44.9 \%$ in children in China [12]. It is a relatively higher burden in themainland of China [4, 13]. The position of the eyes can be normal, but strabismus becomes obvious with fatigue, illness, concentration or reading for a long time, and the patient often shuts his or her eyes when outdoors or in bright light. The patients' eye position often changes between the orthoptic and oblique positions, retaining the opportunity for stereopsis development in the patients. Stereopsis of patients with intermittent exotropia alternates between development and loss, and thus, its near and far stereopsis can be damaged to varying degrees.

It is generally believed that the development of stereopsis begins at approximately 4 months after birth and gradually matures with age. Other study [14] added that foveal stereoacuity is acquired after the age of 6 years. At present, most scholars [15] believe that the near stereopsis of patients with intermittent exotropia is normal and that distant stereopsis is impaired. Lee [16] found that near stereopsis is associated with the age at diagnosis of intermittent exotropia and the best corrected vision, the older the age at diagnosis, the better the corrected vision, and the better the near stereopsis. In patients with intermittent exotropia, stereopsis is unsound with synoptophore fusion function damage appearing earlier and serious, internal and external fusional power dysplasia or internal fusional power dysplasia and external fusional power macroplasia. Besides, they only need image coherence sets and tension sets when they look at the distance, and strabismus is difficult to control. This also explains why children with intermittent exotropia exhibit the preservation of near stereopsis, while far stereopsis is more likely to be damaged.

We found that the patients of intermittent exotropia with myopia accounted for $28.9 \%$, emmetropia accounted for $34.4 \%$, hyperopia accounted for $16.7 \%$, and anisometropia accounted for $20.0 \%$. In children with intermittent exotropia, emmetropia and myopia are the most common, while hyperopia and anisometropia are less common. Ekdawi et al [17] conducted a retrospective study of 184 children under 19 years old who were diagnosed with IXT in the north central part of the United States, and found that the prevalence of myopia was over $90 \%$ in the 20 year old. Some studies have shown that intermittent exotropia with myopia and myopic astigmatism anisometropia are the main ones. There is a slight difference among the studies. This may be due to the difference in ages and sample sizes of the subjects, but the investigations report that intermittent exotropia with myopia is the main one. Because patients with myopia do not use or use less regulation in near fixation, the function of the converge is relatively weakened, leading to further reduction of the regulation and fusion function, and they are thus more prone to develop exotropia. For uncorrected myopia, because of its individual specific low $\mathrm{AC} \mathrm{/} \mathrm{A}$, or without refractive correction, the near visual accommodation is impaired, which leads to the decrease of accommodative converge and leads to exotropia. And intermittent

Table 2 Stereopsis in intermittent exotropia with different refractive states

\begin{tabular}{|c|c|c|c|c|c|c|}
\hline & & Emmetropia & Hyperopia & Myopia & Anisometropia & Total \\
\hline \multirow[t]{3}{*}{ Far stereopsis } & yes & $14(45.2 \%)$ & $5(33.3 \%)$ & $9(34.6 \%)$ & $6(33.3 \%)$ & 34 \\
\hline & No & $17(54.8 \%)$ & 10(66.7\%) & $17(65.4 \%)$ & $12(66.7 \%)$ & 56 \\
\hline & Total & 31 & 15 & 26 & 18 & \\
\hline \multirow[t]{3}{*}{ near stereopsis } & yes & 26(83.9\%) & $10(66.7 \%)$ & $21(80.8 \%)$ & $10(55.6 \%)$ & 67 \\
\hline & No & $5(16.1 \%)$ & $5(33.3 \%)$ & $5(19.2 \%)$ & $8(44.4 \%)$ & 23 \\
\hline & Total & 31 & 15 & 26 & 18 & 90 \\
\hline
\end{tabular}


exotropia is prone to produce visual fatigue, which may have a certain effect on their stereopsis.

Min Yang MD et al [18] found that anisometropia accounted for $17.4 \%$ in 214 patients. Chia et al [19] reported 74 cases of anisometropia among 377 patients with concomitant exotropia (19.63\%), which was consistent with our result that intermittent exotropia with anisometropia accounted for $20.0 \%$ of the cases. Kirwan and O'keefe[20] also believe that stereopsis is related to anisometropia, and that the greater the anisometropia, the greater the binocular visual function. Anisometropia has different degrees of effects on stereopsis; for binocular refraction, every $0.25 \mathrm{D}$ difference can cause a $0.5 \%$ difference in the retinal image is $0.5 \%$. The maximum difference of the retinal image is $5 \%$, that is, the binocular diopter cannot be greater than $2.50 \mathrm{D}$. Beyond this threshold, the binocular images will be unequal in legibility and size, eventually resulting in fusion difficulties and decreased stereopsis. In addition, anisometropia can also cause the retinal images to vary in size, resulting in poor image fusion, high refractive power, and retinal suppression, which can cause exotropia. This study found that the retention rate of near stereopsis in the emmetropia group with intermittent exotropia was significantly higher than that in the anisometropia group $(P=$ 0.030 ), which indicated that anisometropia had a great influence on near stereopsis. Moreover, greater anisometropia can easily lead to refractive amblyopia, and binocular vision must be greatly affected. Although this article did not analyze the children of intermittent exotropia with amblyopia, it is known that anisometropia has a great influence on stereopsis in children with intermittent exotropia, and we should pay attention to it.

Children with hyperopia have poor vision; both distant vision and near vision are markedly impaired. They are less stimulated by normal stimuli and are prone to form amblyopia, which can affect the development of stereopsis in children. We found that near stereopsis in patients with intermittent exotropia was more severe in their hyperopia group than in the emmetropia group and the myopia group, however, the difference was not statistically significant. Kim et al [21] reported that the near stereopsis of patients with intermittent exotropia and hyperopia is worse than that with emmetropia or myopia. Uncorrected hyperopia can get clear eye sight due to less regulation. The low activity collection mechanism results in low AC/A ratio and exotropia. And hyperopia often has the occurrence of amblyopia, which has a great influence on the development of stereovision in children with intermittent exotropia. Therefore, We should do further clinical studies with large samples.

In summary, as in many reports, $[22,23]$ the damage of distant stereopsis in children with intermittent exotropia is more severe than near stereopsis, and the refractive status has some influence on stereopsis in patients with intermittent exotropia, especially anisometropia, it has a greater effect on near stereopsis in children with intermittent exotropia. In addition, patients with refractive error are prone to develop intermittent exotropia. Intermittent exotropia not only affects the appearance but also increase the risk of refractive error in children and greatly affect the stereopsis of patients, which will have some psychological effects on children [24]. Consequently, we should pay attention to the refraction status of children with intermittent exotropia in order to correct the refractive error of these patients in a timely manner and stimulate the convergence function; if so, it will be easy to control the eye position, eventually enabling the children to have a better stereopsis.

\section{Conclusions}

Our study demonstrated that the damage of distant stereopsis in children with intermittent exotropia is more severe than near stereopsis and anisometropia has a greater effect on near stereopsis in children with intermittent exotropia.

\section{Abbreviations}

IXT: Intermittent exotropia

\section{Acknowledgements}

The authors especially thank the patients and their families for taking part in this study.

\section{Availability of data and materials}

The data supporting our findings is contained within the manuscript, or others will be shared upon request.

\section{Authors' contributions}

DH participated in the design of the study, carried out the study and drafted the manuscript and performed the statistical analyses. DJ has participated in the design, carried out the study and the collection of the data. JZ and TP participated in the design of the study, carried out the analysis including statistics. QZ has participated in the study's coordination and has helped to draft the manuscript and has been involved in revising the manuscript carefully. All authors read and approved the final manuscript.

\section{Ethics approval and consent to participate}

The study was approved by the Ethics Committee of the Second Affiliated Hospital of Dalian Medical University and it was performed in accordance with the tenets of the Declaration of Helsinki. A verbal consent was obtained from the parents of patients. (When patients and their parents came to see a doctor, we will ask whether we can collect the data of their children to conduct the research, and we started collecting When they agreed). and the oral consent has been approved by the Ethics Committee of the Second Affiliated Hospital of Dalian Medical University.

\section{Consent for publication}

The parents of patients agreed to collect and publish the data of their children.

\section{Competing interests}

All authors certify that they have no affiliations with or involvement in any organization or entity with any financial interest, or non-financial interest in the subject matter or materials discussed in this manuscript. The authors declare that they have no competing interests.

\section{Publisher's Note}

Springer Nature remains neutral with regard to jurisdictional claims in published maps and institutional affiliations. 
Received: 23 October 2017 Accepted: 13 June 2018

Published online: 19 June 2018

\section{References}

1. Yang $C$, Shen $Y, G u$ Y, et al. Clinical investigation of surgery for intermittent exotropia. J Zhejiang University SCIENCE B. 2008;9:470473.

2. Jung JW, Lee SY. Comparison of the clinical characteristics of intermittent exotropia in children and adults. Korean J Ophthalmol. 2010;24:96-100.

3. Romanchuk KG. Intermittent exotropia: facts, opinions, and unknowns. Am Orthopt J. 2011;61:71-87.

4. Fu J, Li SM, Liu LR, et al. Prevalence of amblyopia and strabismus in a population of 7th-grade junior high school students in Central China: the Anyang childhood eye study (ACES). Ophthalmic Epidemiol. 2014;21:197-203.

5. Kang KT, Lee SY. Relationship between control grade, stereoacuity and surgical success in basic intermittent exotropia [J]. Korean J Ophthalmol. 2015;29(3):173-7.

6. Shin $\mathrm{KH}$, Lee HJ, Lim HT. Ocular torsion among patients with intermittent exotropia: relationships with disease severity factors [J]. Am J Ophthalmol. 2013;155(1):177-82.

7. Hatt SR, Leske DA, Mohney BG, et al. Classification and misclassification of sensory monofixation in intermittent exotropia [J]. Am J Ophthalmol. 2010; 150(1):16-22.

8. Hatt SR, Gnanaraj L. Interventions for intermittent exotropia[J]. Cochrane Database Syst Rev. 2013:5:D3737.

9. Laura Liebermann, C.O.? Intermittent Exotropia: characteristics and overview[J]. Am Orthopt J. 2016:66(1):11-5.

10. Govindan M, Mohney BG, Diehl NN, et al. Incidence and types of childhood exotropia. Ophthalmology. 2005;112:104-8.

11. Jenkins R. Demographics geographic variations in the prevalence and management of exotropia. Am Orthopt J. 1992;42:82-7.

12. Yu CBO, Fan DSP, Wong WY, et al. Changing patterns of strabismus: a decade of experience in Hong Kong. Br J Ophthalmol. 2002;86:854-6.

13. Pan CW, Zhu H, Yu JJ, Ding H, Bai J, Chen J, Yu RB, Liu H. Epidemiology of intermittent Exotropia in preschool children in China.[J]. Optom Vis Sci. 2015:93(1):57-62.

14. Wang J, Hatt SR, O'Connor AR, et al. Final version of the distance randot stereotest: normative data, reliability, and validity. J AAPOS. 2010;14:142-6.

15. Holmes JM, Leske DA, Hatt SR, et al. Stability of near stereoacuity in childhood intermittent exotropia. J Am Associa Pediatric Ophthalmol Strabis. 2011;15:462-7.

16. Lee DS, Kim SJ, Yu YS. The relationship between preoperative and postoperative near stereoacuities and surgical outcomes in intermittent exotropia[J]. Br J Ophthalmol. 2014;98(10):1398-403.

17. Ekdawi NS, Nusz KJ, Diehl NN, et al. The development of myopin among children with intermittent exotropia. Am J Ophthalmol. 2010;149(3):503-7.

18. Yang $M$, Chen J, Shen $T$, Kang Y, Deng D, Lin X, Wu H, Chen Q, Ye X, Li J, Yan J. Clinical characteristics and surgical outcomes in patients with intermittent Exotropia[J]. Medicine (Baltimore). 2016;95(5):e2590.

19. Chia A, Roy L, Seenyen L. Comitant horizontal strabismus: an Asian perspective. Br J Ophthalmol. 2007:91(10):1337-40u.

20. Kirwan C, O'keefe M. Stereopsis in refractive surgery. Am J Ophthalmol. 2006;142(2):218-22.

21. Kim MK, Kim US, Cho MJ, et al. Hyperopie refractive errors as a prognostic factor in intermittent exotropia surgery. Eye(Lond). 2015;29(12):1555-60.

22. Adams WE, Leske DA, Hatt SR, et al. Improvement in distance stereoacuity following surgery for intermittent exotropia. J AAPOS. 2008;12:141-4.

23. Hikoya A. Binocular vision in intermittent exotropia. Folia Ophthalmol Jpn. 2013;6:32-4

24. Glasman P, Cheeseman R, Wong V, et al. Improvement in patients'quality-oflife following strabismus surgery:evaluation of postoperative outcomes using the adult strabismus 20(AS-20) score. Eye. 2013:27:1249-53.

Ready to submit your research? Choose BMC and benefit from:

- fast, convenient online submission

- thorough peer review by experienced researchers in your field

- rapid publication on acceptance

- support for research data, including large and complex data types

- gold Open Access which fosters wider collaboration and increased citations

- maximum visibility for your research: over $100 \mathrm{M}$ website views per year

At BMC, research is always in progress.

Learn more biomedcentral.com/submissions 